\title{
Hybrid Modulation for Modular Voltage Source Inverters with Coupled Reactors
}

\author{
Krzysztof Jakub Szwarc ${ }^{1}$, Pawel Szczepankowski ${ }^{1, *}{ }^{\circledR}$, Janusz Nieznański ${ }^{1}$ (), \\ Cezary Swinarski ${ }^{1}\left(\mathbb{D}\right.$, Alexander Usoltsev ${ }^{2}{ }^{\mathbb{D}}$ and Ryszard Strzelecki ${ }^{1}{ }^{1(1)}$ \\ 1 LINTE ${ }^{2}$ Laboratory, Faculty of Electrical and Control Engineering, Gdańsk University of Technology, \\ 80-216 Gdańsk, Poland; krzysztof.szwarc@pg.edu.pl (K.J.S.); janusz.nieznanski@pg.edu.pl (J.N.); \\ cezary.swinarski@pg.edu.pl (C.S.); ryszard.strzelecki@pg.edu.pl (R.S.) \\ 2 Faculty od Control Systems and Robotics, ITMO University, 191002 Saint Petersburg, Russia; \\ uaa@ets.ifmo.ru \\ * Correspondence: pawel.szczepankowski@pg.edu.pl
}

Received: 3 August 2020; Accepted: 24 August 2020; Published: 27 August 2020

\begin{abstract}
This paper proposes and discusses a concept of a hybrid modulation for the control of modular voltage source inverters with coupled reactors. The use of coupled reactors as the integrating elements leads to significant reduction in the size and weight of the circuit. The proposed modulation combines novel coarsely quantized pulse amplitude modulation (CQ-PAM) and innovative space-vector pulse width modulation (SVPWM). The former enjoys very low transistor switching frequency and low harmonic elimination, while the latter ensures high resolution of amplitude control. The SVPWM is based on the use of barycentric coordinates. The feasibility of the proposed solution is verified by simulations and laboratory tests of a 12-pulse modular voltage source inverters with two-level and three-level component inverters.
\end{abstract}

Keywords: modular; voltage source inverter (VSI); multipulse; 12-pulse; pulse amplitude modulation (PAM); pulse width modulation (PWM); three-level; coupled reactors

\section{Introduction}

The concept of modular voltage source inverters (VSI) with coupled reactors considered in this paper was first reported in [1] (therein dubbed multipulse voltage source converters (VSC) with coupled reactors). The idea has its roots in the well-known multipulse AC-DC converter topologies widely used in a variety of applications, including adjustable speed drives (ASD), high-voltage direct current transmission (HVDC), aircraft power systems, and renewable energy conversion systems [2-5]. The use of multipulse topologies for the DC-AC power conversion has broad coverage in the literature (see, for example, in [6-11]). The topologies proposed in [8-11] are based on the use of a transformer in an integrating circuit, which significantly increases the size of the device and is an expensive solution. If the application does not require galvanic isolation of the DC side from the AC side, the integrated circuit can be based on coupled reactors, as proposed in [1]—a solution which greatly reduces the size and cost of the circuit.

Solutions presented in $[1,7-11]$ are focused on maximizing the achievable magnitude of output voltage, while the control of lower magnitudes is left out. The possible voltage synthesis using all allowed combinations of switch states has not been seriously addressed so far. In this paper, a control of the output voltage of the modular voltage source inverters proposed in [1,12] is considered. These converters contain standard inverter modules, but they are connected by special coupled reactors. The idea of modular VSI with coupled reactors draws on the properties of multipulse diode rectifiers with similar coupled reactors [13-15] and other converters with integrating magnetic circuits $[4,16,17]$. 
Coupled reactors were selected as integrating elements because their rated power is below $20 \%$ of that of a transformer with similar integrating properties $[5,13,14]$. As the inverter modules are connected in parallel, these circuits can be used for high-current systems. Where increased operating voltages are required, multilevel inverters can be used as modules.

To clarify the terminology used in the sequel, note that the idea of "pulses" contained in the term "multipulse" has a simple interpretation in the case of diode or thyristor AC-DC converters: it denotes a section of AC input voltage transferred to the DC output. The "number of pulses", denoted $M$, is used to mean the number of such sections transferred in one fundamental period of the AC voltage. Although for DC-AC inverters with fully controlled power switches this idea of pulses is much less tangible, the number of pulses can still be used for the sake of discussion-as a constructional parameter of the inverter.

Transistor-based modular VSI with coupled reactors can be controlled in a variety of ways. One of the methods mimics the workings of multipulse rectifiers. This method relies on applying a succession of only $M$ inverter voltage vectors in every fundamental period of the synthesized output voltage. This paper demonstrates that by appropriate selection of all available basic voltage vectors, it is possible to achieve coarsely quantized pulse amplitude modulation (CQ-PAM). This control approach, leading to staircase output voltage waveforms, enjoys very low switching frequency of power transistors (equal to the fundamental frequency of the output voltage). A drawback of this modulation method is low amplitude resolution. A workaround might be application of a controlled source of DC voltage, but this option is complex and costly and thus it is left out in this paper.

High-resolution voltage control can be achieved by means of pulse width modulation (PWM). Unlike CQ-PAM, PWM requires relatively high switching frequency (a multiple of the fundamental frequency of output voltage), which can be particularly disadvantageous in high-speed motor drive applications. For example, a two-pole motor operating at 150,000 rpm would call for $5 \mathrm{kHz}$ fundamental frequency of the output voltage, meaning at least several dozens of kilohertz of the transistor switching frequency for PWM controlled inverter. Such high switching frequencies can cause significant mismatches between the transistor on/off commands and the actual turn-on/turn-off timing. What is more, the switching losses and electromagnetic interference resulting from high switching frequency can be prohibitive [18]. The problem of adequate voltage control increases with the increase of motor speed and/or its power. For instance, motor drives in the $1 \mathrm{~kW}$ power range are reported to operate at speeds of 500,000 to 1,000,000 rpm [19,20]. Concerning higher power drives, the authors of [21] report on a $60 \mathrm{~kW}$ drive operating at 100,000 rpm, while the authors of [22] describe a $300 \mathrm{~kW}$ drive operating at $60,000 \mathrm{rpm}$.

To address the above problems, this paper proposes a hybrid modulation combining CQ-PAM and PWM. This approach is capable of combining advantages of PWM (virtually unlimited resolution of voltage control) and those of CQ-PAM (radically reduced switching frequency). The CQ-PAM is intended for use at steady state, while the PWM ensures smooth passage through the transients. A somewhat similar idea of hybrid modulation was proposed in $[23,24]$, but it relies on a combination of two different PWM methods: space-vector pulse width modulation (SVPWM) is used for smooth transients, while selective harmonic elimination PWM (SHE-PWM) is applied for low switching frequency operation at steady state. The CQ-PAM proposed here is even more effective in the reduction of switching frequency than SHE-PWM and-unlike the latter-can easily be computed in real-time. Both CQ-PAM and PWM can rely on selecting and applying appropriate voltage vectors. At steady state, a succession of only $M$ different vectors per fundamental period is used for $M$-pulse inverters, with all vectors being applied for time intervals of the same length. At each interval, the voltage vector closest to the reference vector is selected. Concerning the PWM, vector selection and duty cycle computations are carried out using the barycentric coordinates [25]. This approach speeds up the calculations and allows easy inclusion of the DC link voltage fluctuations in the algorithm. The proposed modulation is exposed and discussed using the simplest case of modular VSI, that is, a 12-pulse inverter with two-level component inverter modules. The application of the proposed 
approach can easily be extended to inverters with higher pulse numbers and/or with multilevel inverter modules [1,12]. Section 2 derives the formula linking the output voltage of modular VSI with coupled reactors with the voltages supplied by component inverter modules and finds the required turns ratio of the coupled reactors. Section 3 presents the proposed modulation method, while Section 4 presents and discusses selected simulation results pertaining to modular VSI using two-level and three-level component inverters and the CQ-PAM. A simulation of the passage between two different steady states using the proposed SVPWM is also demonstrated. The laboratory test results of the same two topologies are presented in Section 5.

\section{The 12-Pulse Modular Voltage Source Inverter with Coupled Reactors}

Twelve-pulse topology has been known as early as in the 1980s [14,26] and widely used in industry to date $[5,27-29]$. However, the first attempts to use this topology (with coupled reactors) in the inverter mode of operation were made only several years ago [1,7]. To the best of the authors' knowledge, there have been no other reports on the use of multipulse topologies for DC-AC conversion. This section analyses the output voltage of the considered modular VSI as a result of vector summation of the component inverter voltages and determines the required turns ratio of the coupled reactors. A schematic diagram of the 12-pulse modular VSI with coupled reactors is shown in Figure 1, while Figure 2 establishes vectorial notation of voltages used in the following analysis.

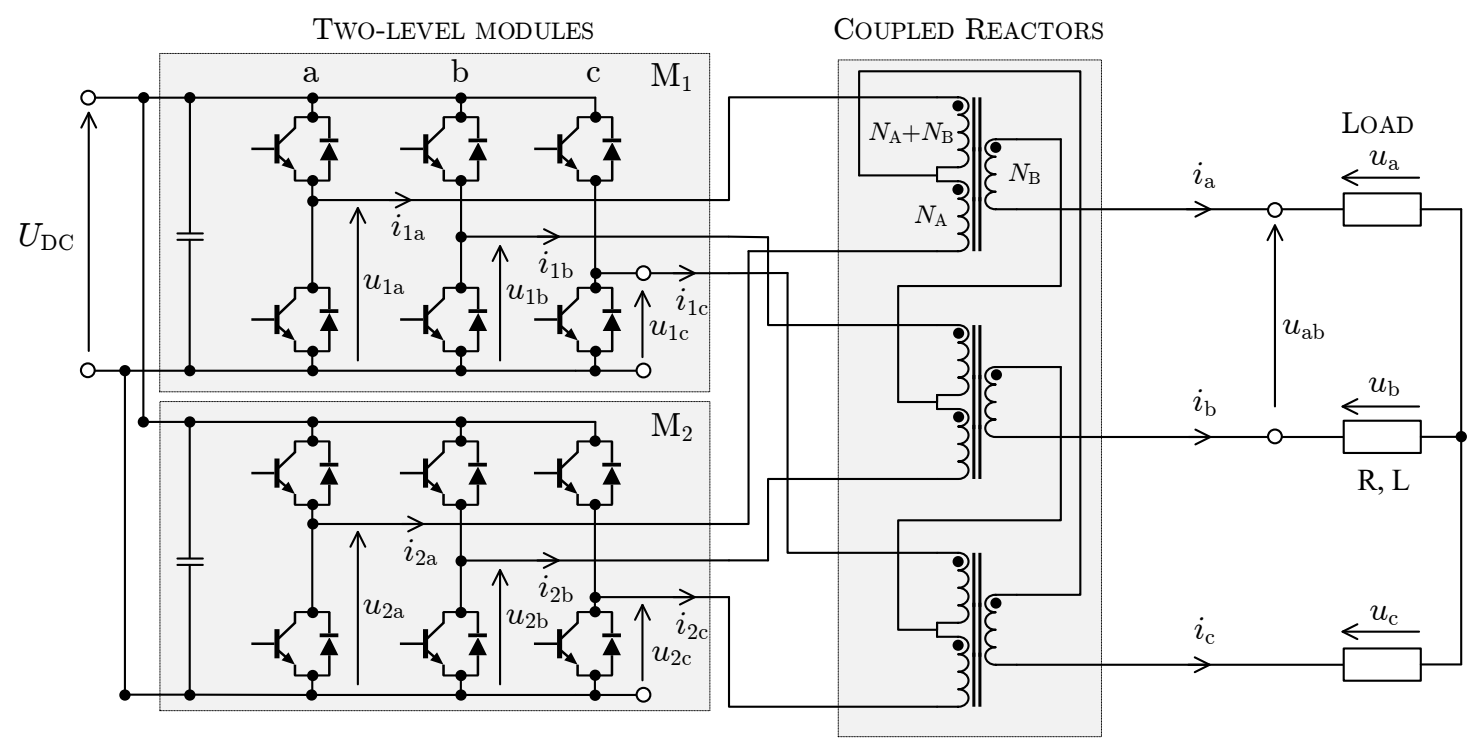

Figure 1. Twelve-pulse modular voltage source inverters (VSI) with coupled reactors.

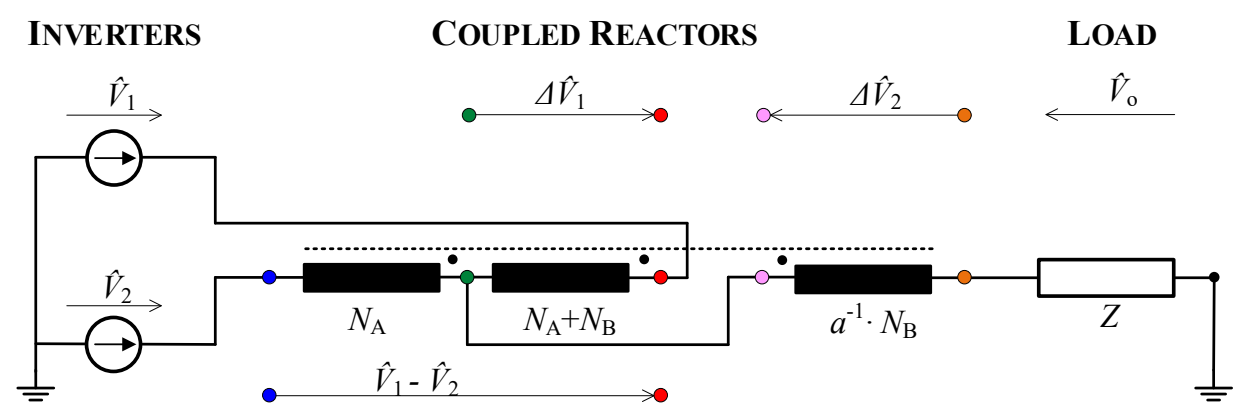

Figure 2. Vectorial equivalent circuit of the 12-pulse modular VSI.

According to the diagram in Figure 2, the output voltage vector of the analyzed modular VSI is given by 


$$
\hat{V}_{\mathrm{o}}=\hat{V}_{1}-\Delta \hat{V}_{1}-\Delta \hat{V}_{2}
$$

where

$$
\begin{aligned}
& \Delta \hat{V}_{1}=\left(\hat{V}_{1}-\hat{V}_{2}\right) \cdot \frac{N_{\mathrm{A}}+N_{\mathrm{B}}}{2 \cdot N_{\mathrm{A}}+N_{\mathrm{B}}} \\
& \Delta \hat{V}_{2}=a^{-1} \cdot\left(\hat{V}_{1}-\hat{V}_{2}\right) \cdot \frac{N_{\mathrm{B}}}{2 \cdot N_{\mathrm{A}}+N_{\mathrm{B}}} \\
& \hat{V}_{1}=U_{\mathrm{M}} \cdot \mathrm{e}^{j \frac{\pi}{3} \cdot \operatorname{ent}\left[\frac{3}{\pi} \omega t\right]}, \hat{V}_{2}=U_{\mathrm{M}} \cdot \mathrm{e}^{j \frac{\pi}{3} \cdot \operatorname{ent}\left[\frac{3}{\pi}(\omega t-\phi)\right]} \\
& a=e^{j \frac{2 \cdot \pi}{3}}
\end{aligned}
$$

Thus, on the basis of Equations (1)-(3), the output voltage can be described by

$$
\hat{V}_{\mathrm{o}}=\hat{V}_{1}-\left(\hat{V}_{1}-\hat{V}_{2}\right) \cdot \frac{N_{\mathrm{A}}+N_{\mathrm{B}}}{2 \cdot N_{\mathrm{A}}+N_{\mathrm{B}}}-a^{-1} \cdot\left(\hat{V}_{1}-\hat{V}_{2}\right) \cdot \frac{N_{\mathrm{B}}}{2 \cdot N_{\mathrm{A}}+N_{\mathrm{B}}}
$$

After simple algebra, Equation (6) can be rewritten as

$$
\hat{V}_{\mathrm{O}}=\hat{V}_{1} \cdot\left(\frac{N_{\mathrm{A}} / N_{\mathrm{B}}-a^{-1}}{2 \cdot N_{\mathrm{A}} / N_{\mathrm{B}}+1}\right)+\hat{V}_{2} \cdot\left(\frac{N_{\mathrm{A}} / N_{\mathrm{B}}-a}{2 \cdot N_{\mathrm{A}} / N_{\mathrm{B}}+1}\right)
$$

It is assumed that the control signals of the inverter modules in the considered 12-pulse system are phase-shifted by $\phi=30^{\circ}$, meaning the same phase shift between vectors $\hat{V}_{1}$ and $\hat{V}_{2}$. As a result, Equation (7) can be converted to

$$
\hat{V}_{\mathrm{O}}=\left(\hat{V}_{1}+\hat{V}_{2}\right) \cdot\left[\frac{\left(N_{\mathrm{A}} / N_{\mathrm{B}}\right)}{2 \cdot\left(N_{\mathrm{A}} / N_{\mathrm{B}}\right)+1}\right]-\left(\hat{V}_{1} \cdot a^{-1}+\hat{V}_{2} \cdot a\right) \cdot\left[\frac{1}{2 \cdot\left(N_{\mathrm{A}} / N_{\mathrm{B}}\right)+1}\right]
$$

In order to determine the appropriate turns ratios of the reactor coils, assume that the magnitude of voltage across a coil is proportional to its number of turns. Then, from Figure 2 it immediately follows that

$$
\frac{\left|\hat{V}_{1}-\hat{V}_{2}\right|}{2 \cdot N_{\mathrm{A}}+N_{\mathrm{B}}}=\frac{\left|\Delta \hat{V}_{1}\right|}{N_{\mathrm{A}}+N_{\mathrm{B}}}=\frac{\left|\Delta \hat{V}_{2}\right|}{N_{\mathrm{B}}}
$$

The desirable turns ratio is such that ensures symmetric contribution of the component voltages $\hat{V}_{1}$ and $\hat{V}_{2}$ to the output voltage $\hat{V}_{\mathrm{o}}$, as illustrated in Figure 3. From the vector diagram in Figure 4, which is an enlargement of the shaded fragment in Figure 3, the following relationship can be found using Thales's theorem,

$$
\frac{\left|\hat{V}_{1}-\hat{V}_{2}\right|}{2} \cdot \tan (\lambda)=\left|\Delta \hat{V}_{2}\right| \cdot \sin \left(60^{\circ}\right)
$$

where $\lambda=\frac{\phi}{2}=15^{\circ}$. Now, using this value of $\lambda$ and substituting Equation (10) to Equation (9), one arrives at

$$
\frac{2 \cdot N_{\mathrm{A}}+N_{\mathrm{B}}}{2} \cdot \tan \left(15^{\circ}\right)=N_{\mathrm{B}} \cdot \sin \left(60^{\circ}\right)
$$

whereupon, using basic trigonometric relationships, an explicit formula for the required turns ratio of the reactor coils is found:

$$
\frac{N_{\mathrm{A}}}{N_{\mathrm{B}}}=\frac{\sin \left(60^{\circ}-15^{\circ}\right)}{\sin \left(15^{\circ}\right)}=2.732
$$




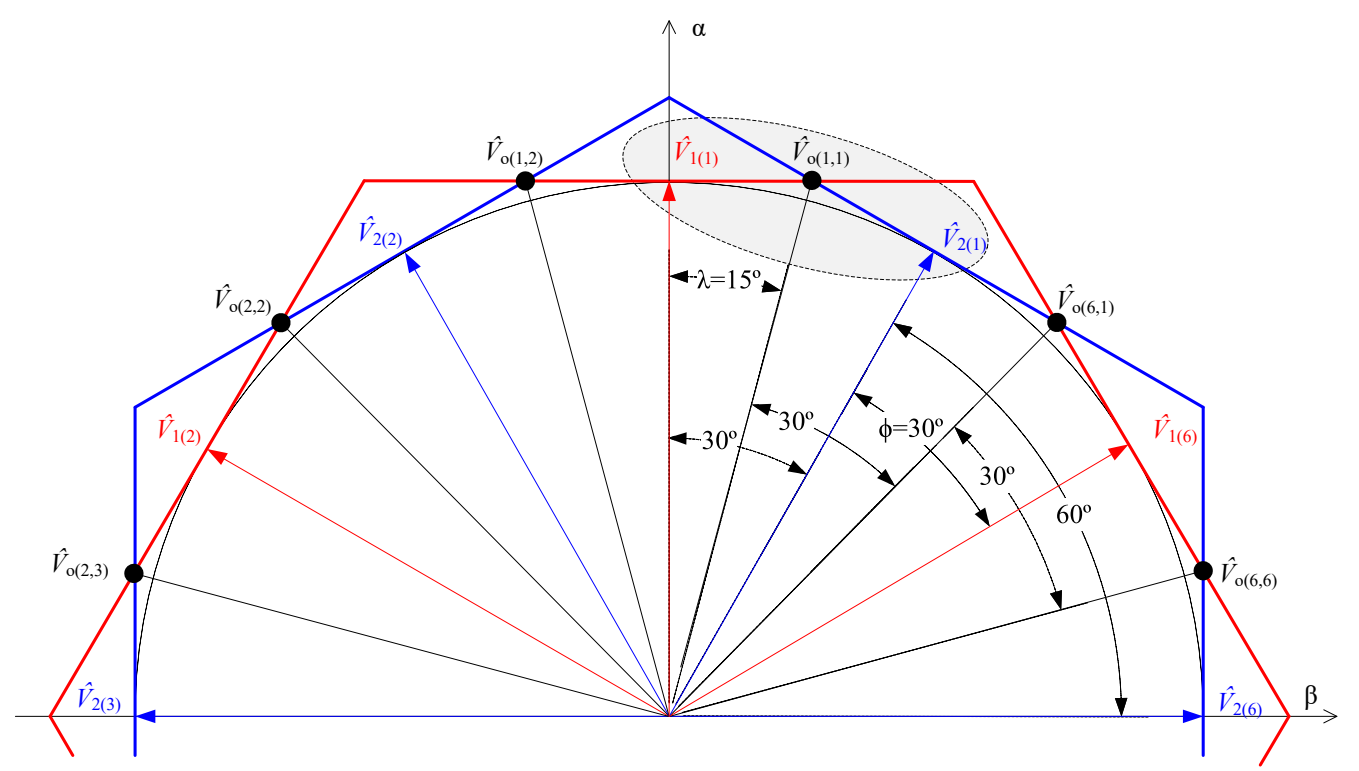

Figure 3. Desirable positions of basic output vectors of component inverters in the 12-pulse modular VSI.

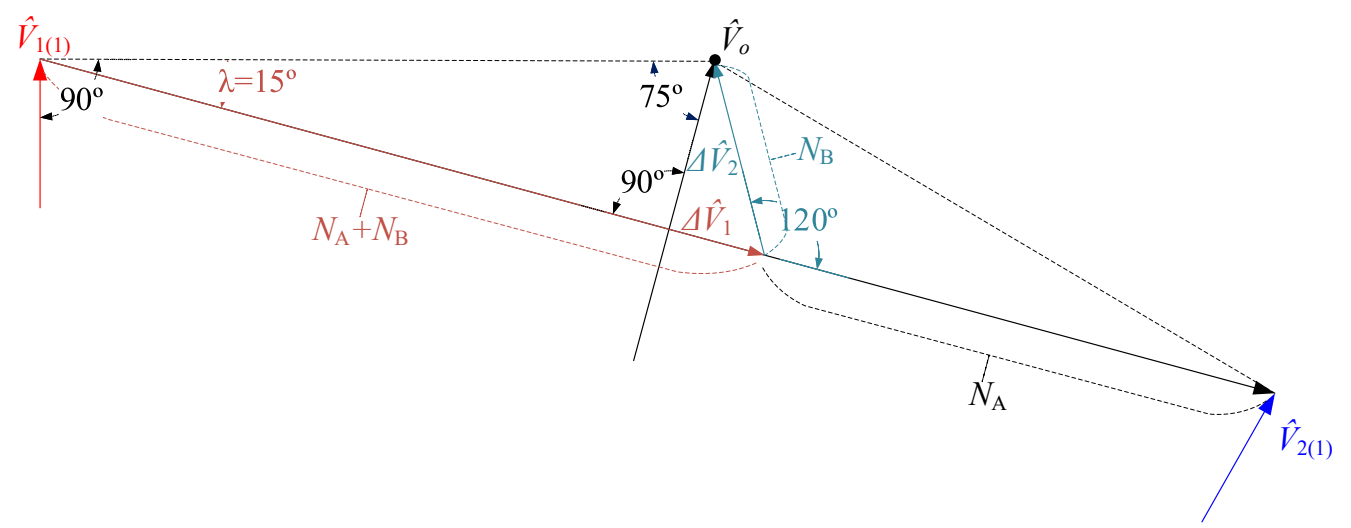

Figure 4. Details of geometric relationship between the output vector $\hat{V}_{\mathrm{o}}$ of the 12-pulse modular VSI and component vectors $\hat{V}_{1}$ and $\hat{V}_{2}$.

\section{Proposed Hybrid Modulation Method}

In one of the proposed operation modes of the considered modular VSI, transistors of inverter modules commute with the fundamental output frequency, which means significant reduction of switching losses and electromagnetic interference (EMI) distortion, and allows high frequencies of output voltages. The problem with this type of control, referred to as the CQ-PAM, is the limited resolution of the output voltage. The proposed solution is the use of PWM as a complementary control method. Both modulation techniques are based on appropriate selection and timing of the available basic vectors, that is, voltage vectors corresponding directly to the on/off states of inverter switches. These vectors can be considered points on a two dimensional $\alpha \beta$ plane. The basic vector diagram for the considered 12-pulse system is shown in Figure 5a. The basic vectors in Figure 5 are obtained in two steps. First, the leg voltages of component inverter modules (marked in Figure 1) are transformed to phase voltages of the modular VSI by

$$
\left[\begin{array}{l}
u_{\mathrm{a}} \\
u_{\mathrm{b}} \\
u_{\mathrm{c}}
\end{array}\right]=\left[\begin{array}{lll}
u_{1 \mathrm{~b}} & u_{1 \mathrm{~b}}-u_{2 \mathrm{~b}} & u_{1 \mathrm{a}}-u_{2 \mathrm{a}} \\
u_{1 \mathrm{c}} & u_{1 \mathrm{c}}-u_{2 \mathrm{c}} & u_{1 \mathrm{~b}}-u_{2 \mathrm{~b}} \\
u_{1 \mathrm{a}} & u_{1 \mathrm{a}}-u_{2 \mathrm{a}} & u_{1 \mathrm{c}}-u_{2 \mathrm{c}}
\end{array}\right] \cdot\left[\begin{array}{c}
1 \\
-k_{1} \\
-k_{2}
\end{array}\right]
$$

where 


$$
k_{1}=\frac{N_{\mathrm{A}}+N_{\mathrm{B}}}{2 \cdot N_{\mathrm{A}}+N_{\mathrm{B}}}, k_{2}=\frac{N_{\mathrm{B}}}{2 \cdot N_{\mathrm{A}}+N_{\mathrm{B}}}
$$

Then, the $\alpha \beta$ coordinates of the corresponding basic vectors $\left(\hat{V}_{\mathrm{O}}\right)$ are determined by the Clarke transformation:

$$
\left[\begin{array}{l}
v_{\alpha} \\
v_{\beta}
\end{array}\right]=\left[\begin{array}{ccc}
\frac{2}{3} & -\frac{1}{3} & -\frac{1}{3} \\
0 & \frac{1}{\sqrt{3}} & -\frac{1}{\sqrt{3}}
\end{array}\right] \cdot\left[\begin{array}{l}
u_{\mathrm{a}} \\
u_{\mathrm{b}} \\
u_{\mathrm{c}}
\end{array}\right]
$$

In general, the number of different basic vectors for an $M$-pulse inverter with $l$-level inverter modules is $l^{\frac{M}{2}}$. Therefore, the considered 12-pulse converter exhibits 64 different basic vectors.
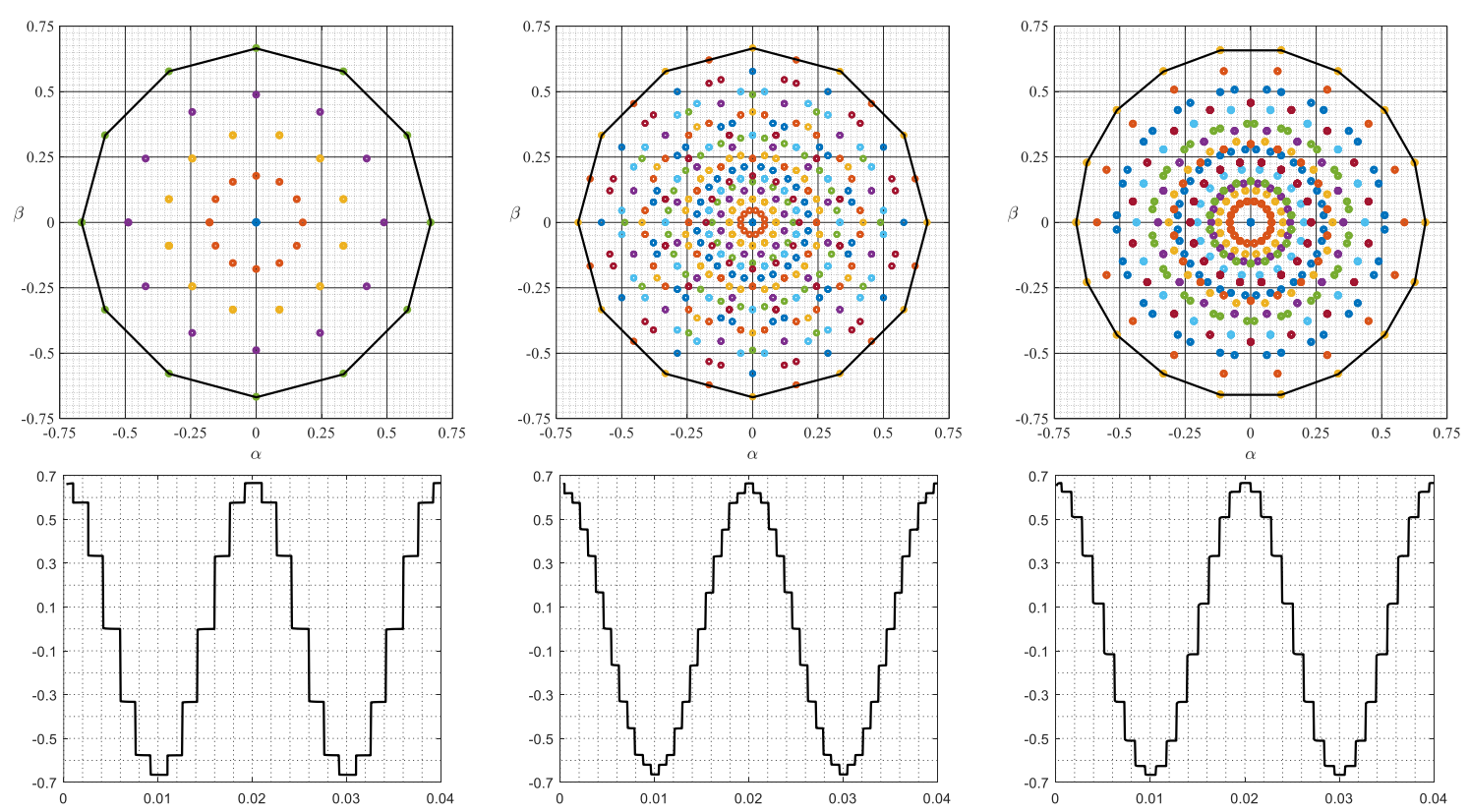

a) 12-pulse 2-level modules

b) 12-pulse 3-level modules

c) 18-pulse 2-level modules

Figure 5. Space-vector diagrams of three modular VSI topologies (top graphs) and example voltage waveforms (bottom graphs) corresponding to the sequences of vectors indicated by connecting lines:

(a) 12-pulse 2-level modules; (b) 12-pulse 3-level modules; (c) 18-pulse 2-level modules.

\subsection{Coarsely Quantized Pulse Amplitude Modulation (CQ-PAM)}

Basically, the CQ-PAM involves applying a succession of only $M$ different basic vectors per fundamental period, with all vectors having the same magnitude and being applied for equal-length time intervals. The selection of basic vectors relies on the criterion of proximity between the reference vector and the basic vectors. As seen in Figure $5 \mathrm{a}$, for $M=12$ and $l=2$ only four different non-zero magnitudes are available, meaning very limited resolution. However, as can be noticed in Figure $5 b, c$, as the number of inverter modules or inverter voltage levels increases, the resolution of the CQ-PAM significantly rises-for an 18-pulse modular VSI it is 16 magnitudes and for a 12-pulse modular VSI with three-level modules it is 24 magnitudes.

For increased $M$ and/or $l$, some neighboring magnitudes are close to each other, and thus it can be beneficial to use their combinations rather than stick to the same-magnitude principle. This option is illustrated in Figure 5b for the 12-pulse VSI with three-level modules: the sequence of vectors leading to the waveform shown in the lower graph is a succession of 24 (that is, $2 \cdot M$ ) basic vectors indicated in the upper graph; the magnitude of the shorter vectors is $\cos \left(\frac{\pi}{M}\right)=\sim 0.97$ times that of the longer vectors. What is more, some magnitudes can be represented by more than $M$ vectors. For instance, 
the 12-pulse VSI with three-level modules has seven magnitudes represented by $2 \cdot M=24$ basic vectors. Again, this fact can be exploited in the CQ-PAM algorithm.

\subsection{Space Vector Pulse Width Modulation (SVPWM)}

To ensure virtually unlimited amplitude resolution of output voltage control, the PWM can be used whenever necessary or desirable. An economic solution might be the PWM discussed in $[17,30]$ for 12-pulse rectifiers. However, this PWM technique offers only limited voltage control range and does not take advantage of the natural elimination of low harmonics in multipulse systems. Another candidate solution might be selective harmonic elimination PWM (SHE-PWM), which allows to decrease the switching frequency and remove a set of selected harmonics. Such a method was applied for parallel inverters driving a single load separated by line reactors [31]. However, this method requires precomputation of the appropriate PWM patterns, which is hardly possible in real-time [32,33]. This paper proposes an innovative space-vector PWM (SVPWM) based on barycentric coordinates.

In most cases considered in the literature, the output vectors are synthesized using the nearest three vectors (NTV) approach. A similar approach is adopted in this paper. In order to select the nearest basic vectors, the magnitude of reference vector $\left(V_{\text {ref }}\right)$ is compared with the available magnitudes of inverter basic vectors. The comparisons permit determining two neighboring magnitudes between which the reference vector is located. The closest two basic vectors of either magnitude are then searched for using a simple sorting algorithm and the following vector distance relationship

$$
\Delta V=\sqrt{\left(V_{\text {ref } \alpha}-v_{\alpha}\right)^{2}+\left(V_{\text {ref } \beta}-v_{\beta}\right)^{2}}
$$

The so obtained closest vectors can be considered vertices of a quadrangle ABCD, as illustrated in Figure 6. The quadrangle can be divided into four triangles. The tasks of the modulation include selecting the most appropriate of the triangles and computing the duty cycles of the three corresponding basic vectors.
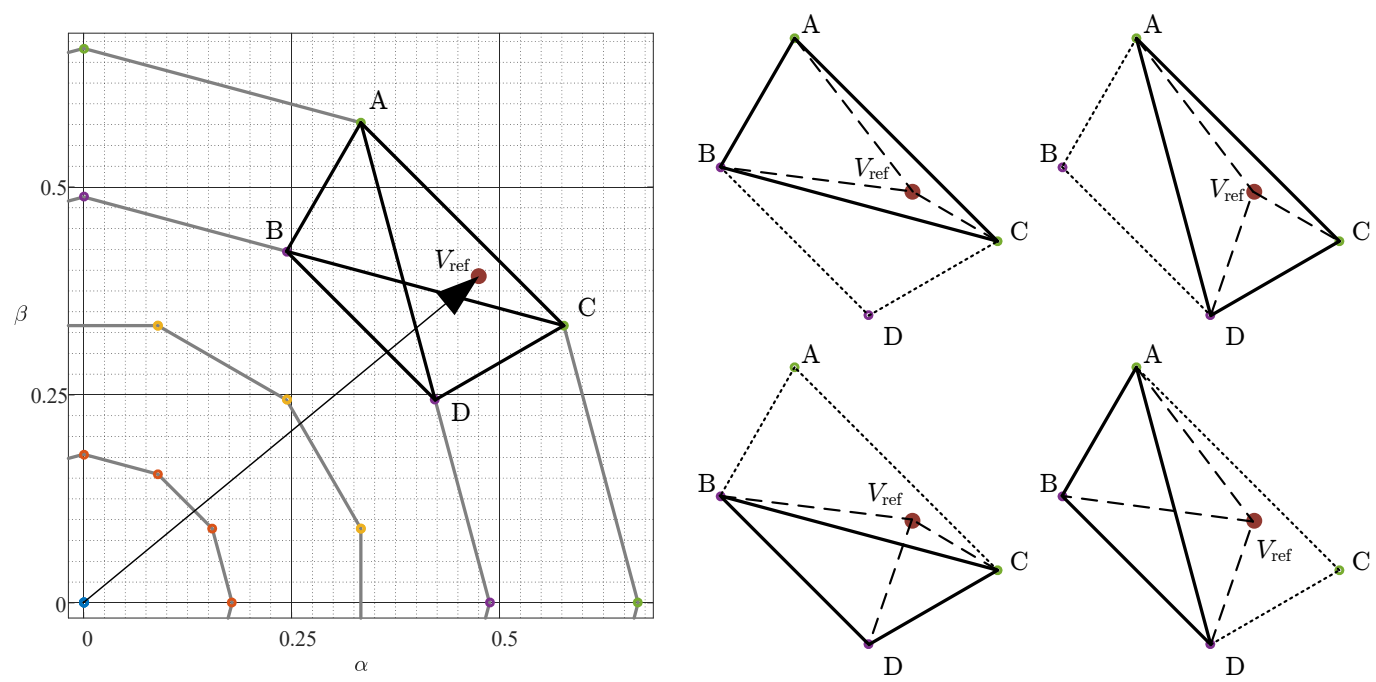

Figure 6. Example reference vector and its representation by means of barycentric coordinates.

Both of the above indicated tasks can be achieved with the aid of barycentric coordinates [25]. Unlike the most popular methods of PWM computations, which are based on trigonometric functions, the use of barycentric coordinates avoids the related inconvenience. Consider the reference vector in Figure 6. It can be considered a point inside triangle ABC or triangle ACD. To fix attention, let us focus on the former triangle. The computation of duty cycles of the corresponding basic vectors is effectively means expressing the position of the reference vector as a linear combination of basic vectors. This is equivalent to expressing the Cartesian coordinates of a point inside a triangle by the barycentric 
coordinates of that point. Thus, the coordinates of vector $\left(V_{\text {ref }}\right)$ in Figure 6 can be expressed by the coordinates of points $\mathrm{A}, \mathrm{B}$, and $\mathrm{C}$ :

$$
\left[\begin{array}{c}
V_{\text {ref } \alpha} \\
V_{\operatorname{ref} \beta}
\end{array}\right]=\left[\begin{array}{lll}
A_{\alpha} & B_{\alpha} & C_{\alpha} \\
A_{\beta} & B_{\beta} & C_{\beta}
\end{array}\right]\left[\begin{array}{c}
N_{1} \\
N_{2} \\
N_{3}
\end{array}\right]
$$

where $N_{1}, N_{2}$, and $N_{3}$ are the barycentric coordinates of $V_{\text {ref }}$, which can be calculated from

$$
\left[\begin{array}{lll}
N_{1} & N_{2} & N_{3}
\end{array}\right]=\left[\begin{array}{lll}
\frac{\triangle_{\text {ref }} B C}{\triangle_{A B C}} & \frac{\triangle_{\text {ref }} A C}{\triangle_{A B C}} & \frac{\triangle_{\text {ref }} A B}{\triangle_{A B C}}
\end{array}\right]
$$

with the $\triangle_{i j k}$ symbols representing the areas of the small triangles defined inside triangle $\mathrm{ABC}$ by the vertices of the latter and $V_{\text {ref. }}$. Stated differently, the barycentric coordinates are equal to the normalized areas of their corresponding small triangles. These areas can be computed direct from the $\alpha \beta$ coordinates of the appropriate basic vectors by

$$
\triangle_{i j k}=\frac{1}{2} \cdot\left|\left[\begin{array}{ccc}
v_{i \alpha} & v_{i \beta} & 1 \\
v_{j \alpha} & v_{j \beta} & 1 \\
v_{k \alpha} & v_{k \beta} & 1
\end{array}\right]\right|
$$

A useful property of the barycentric coordinates is that their sum is equal to unity if they are calculated for a point inside a triangle (e.g., $V_{\text {ref }}$ in the triangle $\mathrm{ABC}$ or $\mathrm{ACD}$ in Figure 6), but is greater if the point lies outside the triangle (e.g., $V_{\text {ref }}$ in the triangle $\mathrm{ABD}$ or $\mathrm{BCD}$ in Figure 6). Thus, a uniform and effective method of finding a triangle or triangles containing a reference vector may be to calculate some candidate barycentric coordinates and then select the smallest (ideally 1 ).

As can be seen in Figure 6, the reference vector can be located inside two different triangles, and so some additional selection criterion is necessary to make the choice unique. The proposed algorithm selects the triangle for which the distance between the reference vector and the centroid $\left(C_{\triangle}\right)$ is smaller. This criterion was adopted in order to minimize the occurrence of narrow pulses. The coordinates of the centroids are calculated as arithmetic means of the coordinates of vertices:

$$
C_{\triangle}=\left[\begin{array}{l}
C_{\triangle \alpha} \\
C_{\triangle \beta}
\end{array}\right]=\left[\begin{array}{c}
\frac{1}{3}\left(v_{i \alpha}+v_{j \alpha}+v_{k \alpha}\right) \\
\frac{1}{3}\left(v_{i \beta}+v_{j \beta}+v_{k \beta}\right)
\end{array}\right]
$$

The distance between $V_{\text {ref }}$ and the centroids is determined by Equation (16).

Although the proposed computational approach may seem rather complex for a system with only 64 space vectors, the practical target for the proposed method is modular VSI inverters with higher number of pulses $M$ (notably, 18- and 24-pulse circuits) and using multilevel component inverters [1]. For such systems, the number of basic space vectors increases rapidly with $M$ and the number of inverter levels (see Figure 5), as shown in Table 1.

Table 1. Number of space vectors for $M$-pulse modular VSI with $l$-level modules.

\begin{tabular}{cccc}
\hline $\boldsymbol{l} \backslash \boldsymbol{M}$ & 12-Pulse & 18-Pulse & 24-Pulse \\
\hline 2-level & 64 & 512 & 4096 \\
3-level & 729 & 19,683 & 531,683 \\
4-level & 4096 & 262,144 & $16,777,216$ \\
\hline
\end{tabular}

It is also important to note that with the increasing number of pulses and levels, the number of available magnitudes of inverter basic vectors also increases rapidly (e.g., 18-pulse and 24-pulse inverters with two-level modules have 16 and 67 output voltage magnitudes respectively and 12-pulse modular VSI with three-level modules has 23 output voltage magnitudes), rendering the CQ-PAM 
mode a true alternative to the PWM for steady-state operation, with the proposed SVPWM becoming a method for increasing the voltage control resolution, especially during transients.

\subsection{Selection of Modulation Method}

The selection between CQ-PAM and SVPWM can be based on a variety of criteria, depending on the application (for instance the frequency criterion: SVPWM to be selected for lower fundamental frequencies, e.g., during the start-up, and CQ-PAM for higher fundamental frequencies). For the purpose of this study, the following magnitude proximity criterion is used; CQ-PAM is selected if the reference vector lies inside an annulus $A_{i}$ defined by two circles-one inscribed in and the other described on a certain $M$-gon made of vectors of the $i$ th magnitude $\left(V_{i}\right)$; otherwise, SVPWM is chosen.

$$
A_{i}=\left\langle\cos \left(\frac{\pi}{M}\right) \cdot V_{i}, V_{i}\right\rangle
$$

The selection of the modulation method can be based on a decision diagram shown in Figure 7.

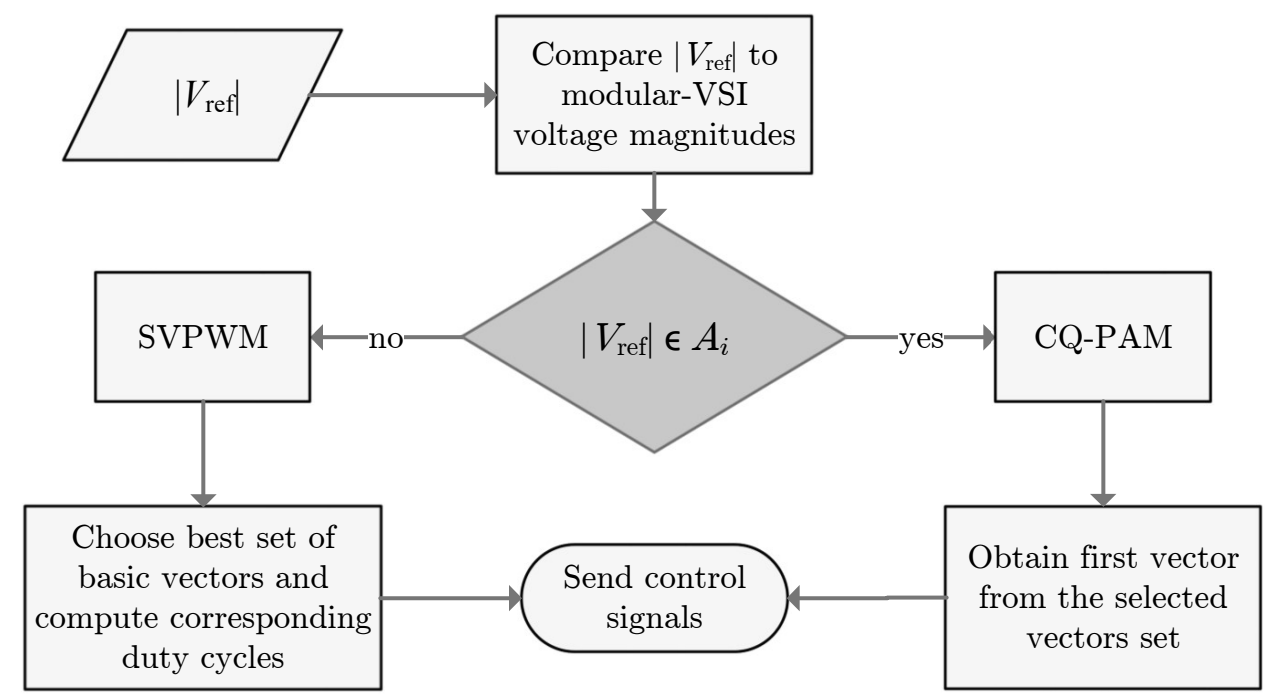

Figure 7. Control algorithm diagram.

\section{Simulation Results}

The proposed concept of output voltage control for modular VSI with coupled reactors has been verified using the PSIM11 simulation software and the Matlab environment. The simulated topologies included the 12-pulse inverter with two-level modules (Figure 1) and the 12-pulse inverter with three-level modules (Figure 8). The most important circuit and control parameters are given in Table 2.

THREE-LEVEL MODULES

COUPLED REACTORS

LOAD

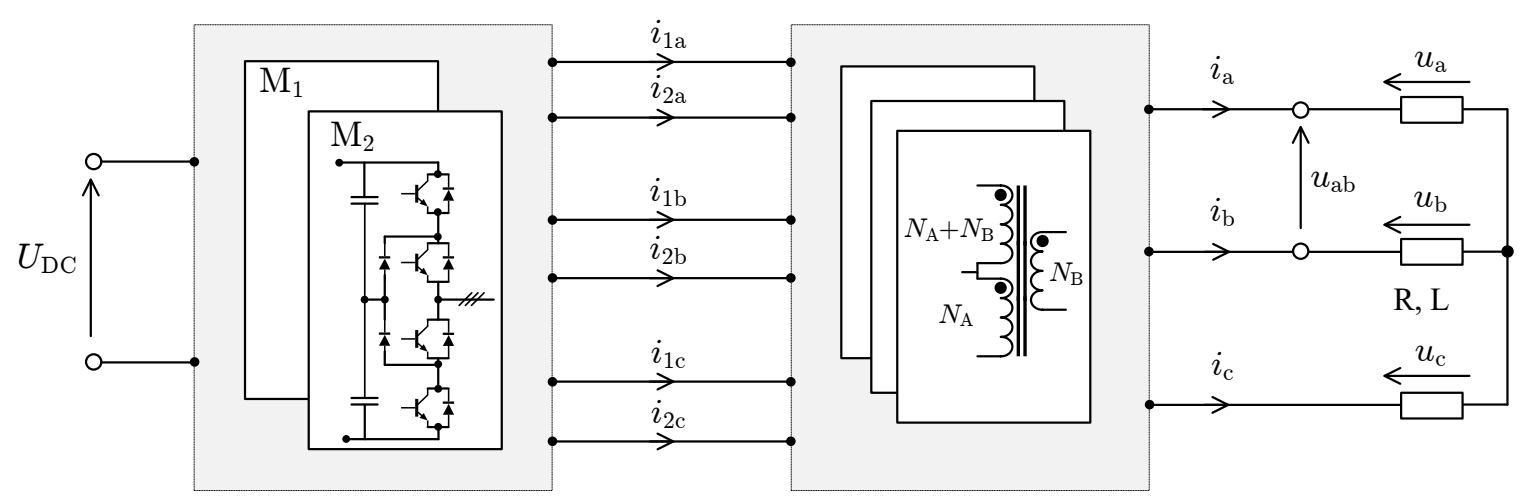

Figure 8. Twelve-pulse modular VSI with coupled reactors and three-level modules. 
Table 2. Circuit and modulation parameters used in simulation.

\begin{tabular}{ccl}
\hline Symbol & Value & Description \\
\hline$U_{\mathrm{DC}}$ & $100 \mathrm{~V}$ & DC source voltage \\
$\mathrm{R}$ & $10 \Omega$ & load resistance \\
$\mathrm{L}$ & $0.2 \mathrm{mH}$ & load inductance \\
$f_{\mathrm{O}}$ & $1000 \mathrm{~Hz}$ & output fundamental frequency \\
$f_{\mathrm{m}}$ & $30,000 \mathrm{~Hz}$ & modulation frequency \\
$N_{\mathrm{A}}$ & 153 & number of turns of coils A \\
$N_{\mathrm{B}}$ & 56 & number of turns of coils B \\
\hline
\end{tabular}

The operation of the considered modular VSI with CQ-PAM is illustrated in Figure 9. Characteristic values for output voltages and currents for this control mode are given in Table 3. A comparison of output voltage and current waveforms for two-level and three-level inverter modules is shown in Figure 10. To demonstrate how low the switching frequency is in relation to the output voltage frequency, the above figure also visualizes the leg voltage $u_{1}$ a waveform (scaled down to $25 \%$ in Figures 9 and 10). The output voltages shown in Figure 9 are the time waveforms corresponding to 12-pulse space-vector diagrams presented in Figure 5a. Later in this section a passage is illustrated between two steady-state operating points with the aid of SVPWM invoked during the transients (Figure 11).

Table 3. Number of switch commutations per period of the output voltage and the THD (of voltages and currents) for the coarsely quantized pulse amplitude modulation (CQ-PAM) presented in Figure 9.

\begin{tabular}{cccc}
\hline $\boldsymbol{m}_{\mathbf{a}}$ & Commutations & THD U (\%) & THD I (\%) \\
\hline 0.179 & 5 & 15.58 & 8.4 \\
0.345 & 3 & 15.58 & 8.4 \\
0.488 & 3 & 15.58 & 8.4 \\
0.67 & 1 & 15.58 & 8.4 \\
\hline
\end{tabular}

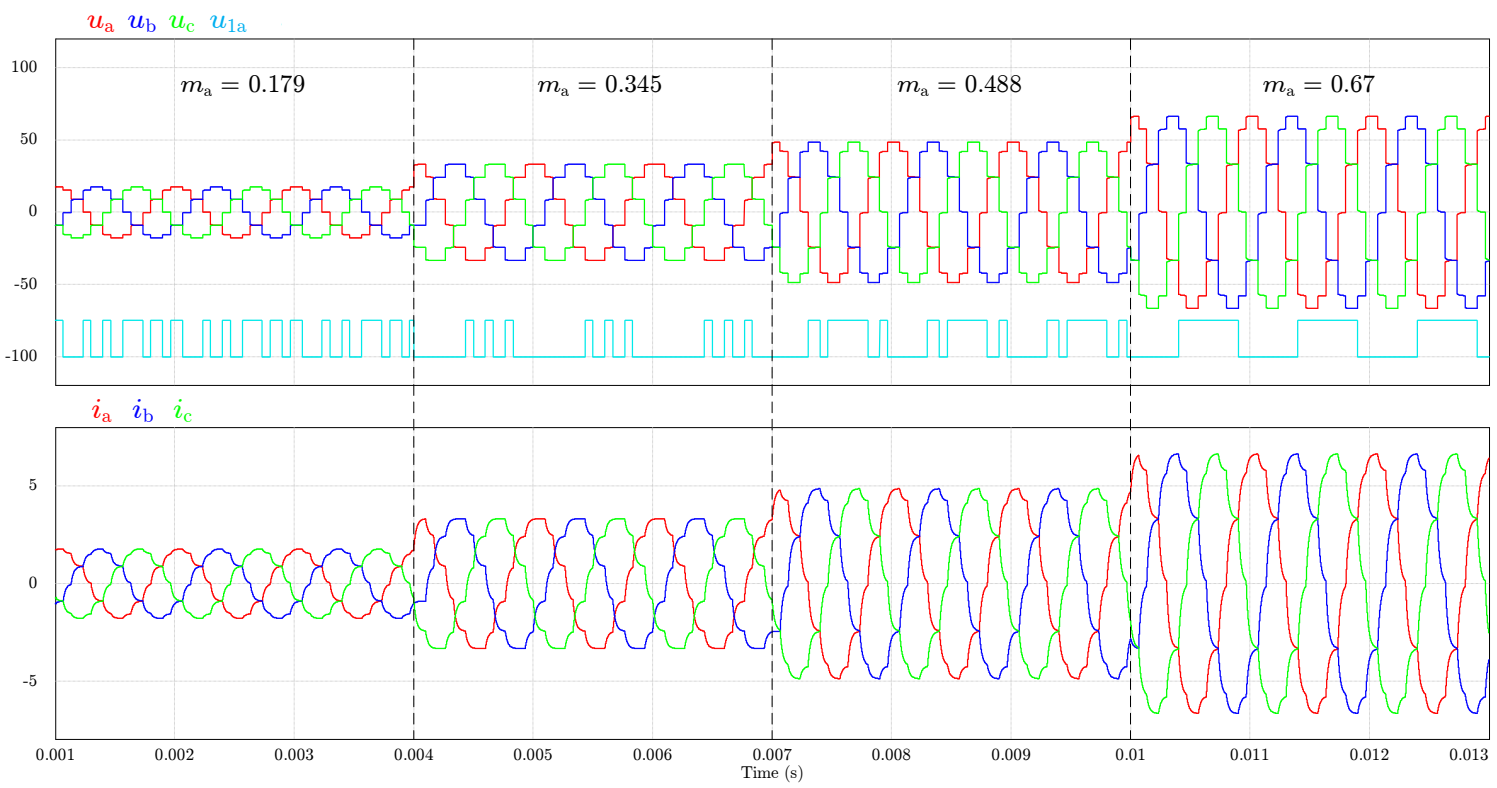

Figure 9. Output voltage and current waveforms of the 12-pulse modular VSI with CQ-PAM control.

Figure 10 illustrates the maximum-magnitude and minimum-magnitude output voltages of 12-pulse modular VSIs with two-level and three-level modules, and the corresponding currents and leg voltages. As can be seen, the use of multilevel modules can increase the number of output voltage steps, so that the total harmonic distortion (THD) of the output voltage decreases (from 15.58\% for 
two-level modules to $10 \%$ for three-level modules), and so does the THD of output currents (from $8.4 \%$ to $4.4 \%$ respectively). Moreover, for multilevel modules the dynamic range and resolution of output voltage magnitudes increases compared to the two-level modules. The minimum voltage for modular VSI with three-level modules is about four times lower than for two-level modules. The number of available non-zero voltage magnitudes also increases-from four in the case of two-level modules to twenty-three for three-level modules.

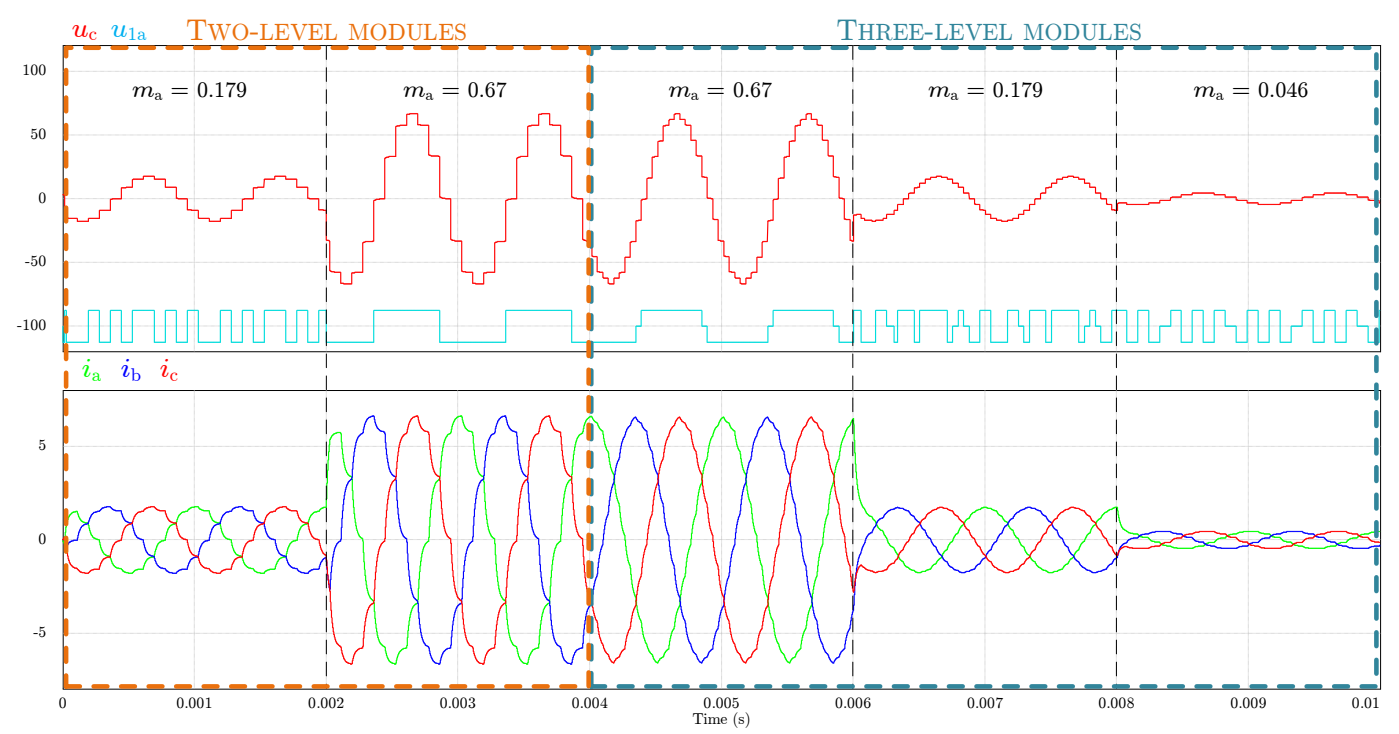

Figure 10. Example voltage and current waveforms of the 12-pulse modular VSI with two-level (left) and three-level (right) modules.

Figure 11 illustrates combined use of the proposed SVPWM and the CQ-PAM, ensuring smooth passage between different steady states. In this particular example the passage is between steady states at $m_{\mathrm{a}}=0.345$ and $m_{\mathrm{a}}=0.488$.

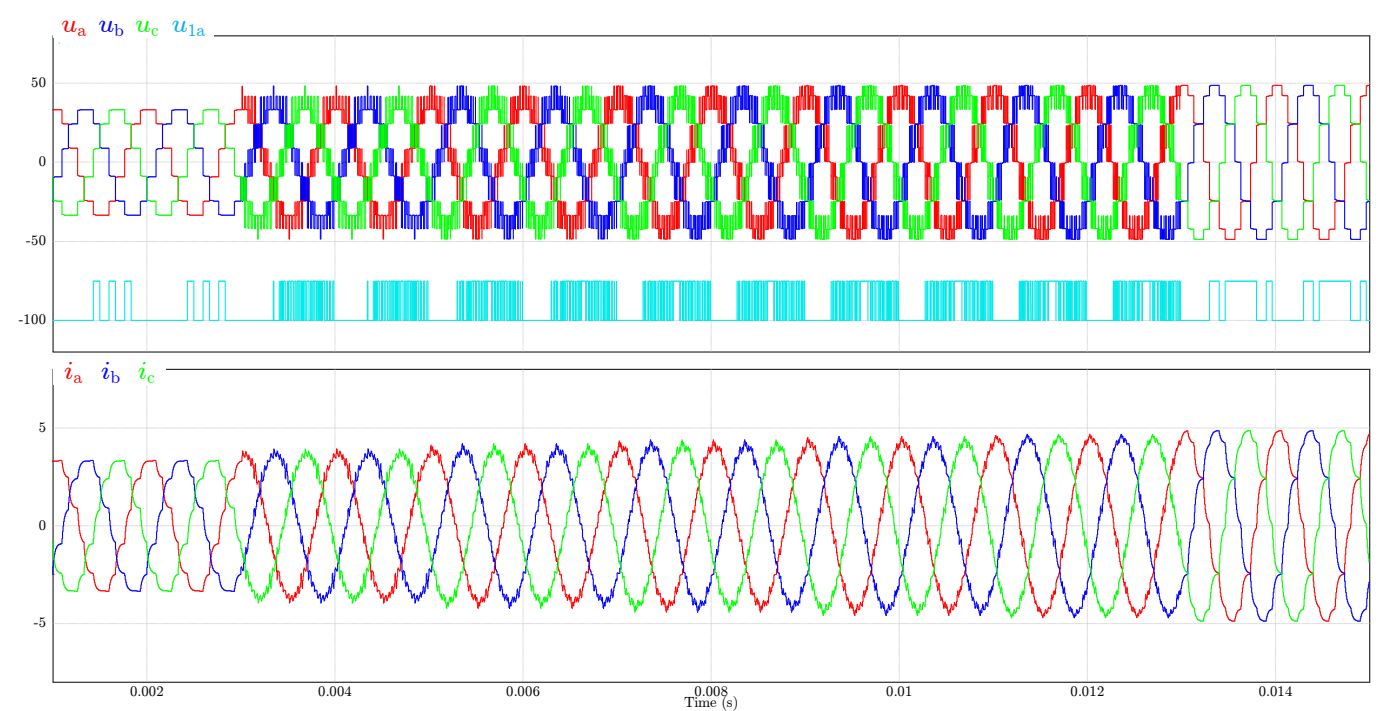

Figure 11. Example output voltage and current waveforms of the 12-pulse modular VSI during the passage between two different steady states.

\section{Laboratory Test Results}

The laboratory tests have been performed using two prototypes of modular VSI with coupled reactors: one using two-level inverter modules, and the other equipped with three-level modules. 
The laboratory setup is presented in Figure 12. The most important circuit and control parameters are the same in both cases and identical to those used in the simulation (cf. Table 2). Measurements were taken by a Tektronix MDO4104B-3 oscilloscope. The control board contained a the two-core Texas Instruments digital signal processor TMS320C6672 and an Intel programmable logic device CYCLONE V. The coupled reactors shown in Figure 12 were designed for $30 \mathrm{~kW}$ (10 kW each) and rated frequency of $2.5 \mathrm{kHz}$. The numbers of turns of reactor coils are given in Table 2.

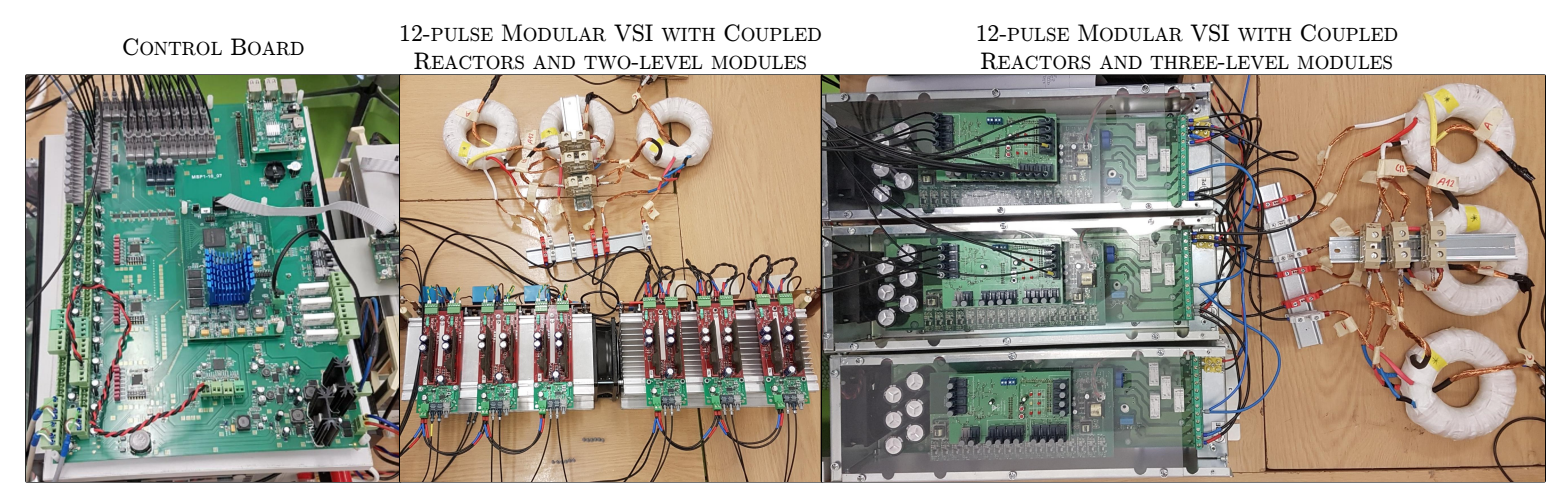

Figure 12. The laboratory set-up.

Figure 13 illustrates output phase voltages and currents, component inverter leg voltages, and the voltage across coil $N_{\mathrm{B}}$ for all output voltage magnitudes and parameters listed in Table 2 (for CQ-PAM controlled VSI with two-level modules). The waveforms correspond to the simulation results shown in Figure 9. The laboratory test results match the results of the simulation, except for the voltage spikes appearing between the steps in the laboratory waveforms. This is a consequence of the use of dead time and the fact that several inverter legs are switched simultaneously (for voltage magnitudes other than the maximum one). However, it can be noted that the amplitudes of these spikes are not significant (smaller than $U_{\mathrm{DC}}$ ) and do not noticeably affect the current waveforms. The inverter leg voltages indicate the frequency with which the power switches commute (the waveforms confirm the data in Table 3). For the maximum available output voltage the switching frequency is equal to the fundamental output voltage frequency (in this case $1 \mathrm{kHz}$ ), and for the smallest CQ-PAM controlled output voltage it is equal to five times the output voltage frequency $(5 \mathrm{kHz})$. One of the most important features distinguishing the coupled reactors from other magnetic integrating elements is their low rated power (related to the power of the overall system). To illustrate this feature, Figure 13 shows the voltage across the $N_{\mathrm{B}}$ coil of the coupling reactor. The voltage is not only significantly lower than $U_{\mathrm{DC}}$, but may even assume values close to zero for some steps (depending on the output voltage magnitude). Therefore, the power transmitted through the reactor is only a fraction of the rated power of the inverter.

The hybrid modulation discussed in Section 3 is based on a combination of the CQ-PAM specific to the considered topologies, and the universal SVPWM-using the proposed computational approach based on barycentric coordinates. Figure 14 illustrates the phase voltages as well as phase-to-phase voltages for both modulation strategies. The voltages in Figure 14 correspond to $m_{\mathrm{a}}=0.67$ for CQ-PAM, and $m_{\mathrm{a}}=0.62$ for SVPWM. Figure 15 shows the voltages and currents obtained by SVPWM for two operating points: $m_{\mathrm{a}}=0.61$ and $m_{\mathrm{a}}=0.42$. The fundamental frequency was $1000 \mathrm{~Hz}$ for the higher output voltage and $600 \mathrm{~Hz}$ for the lower. 


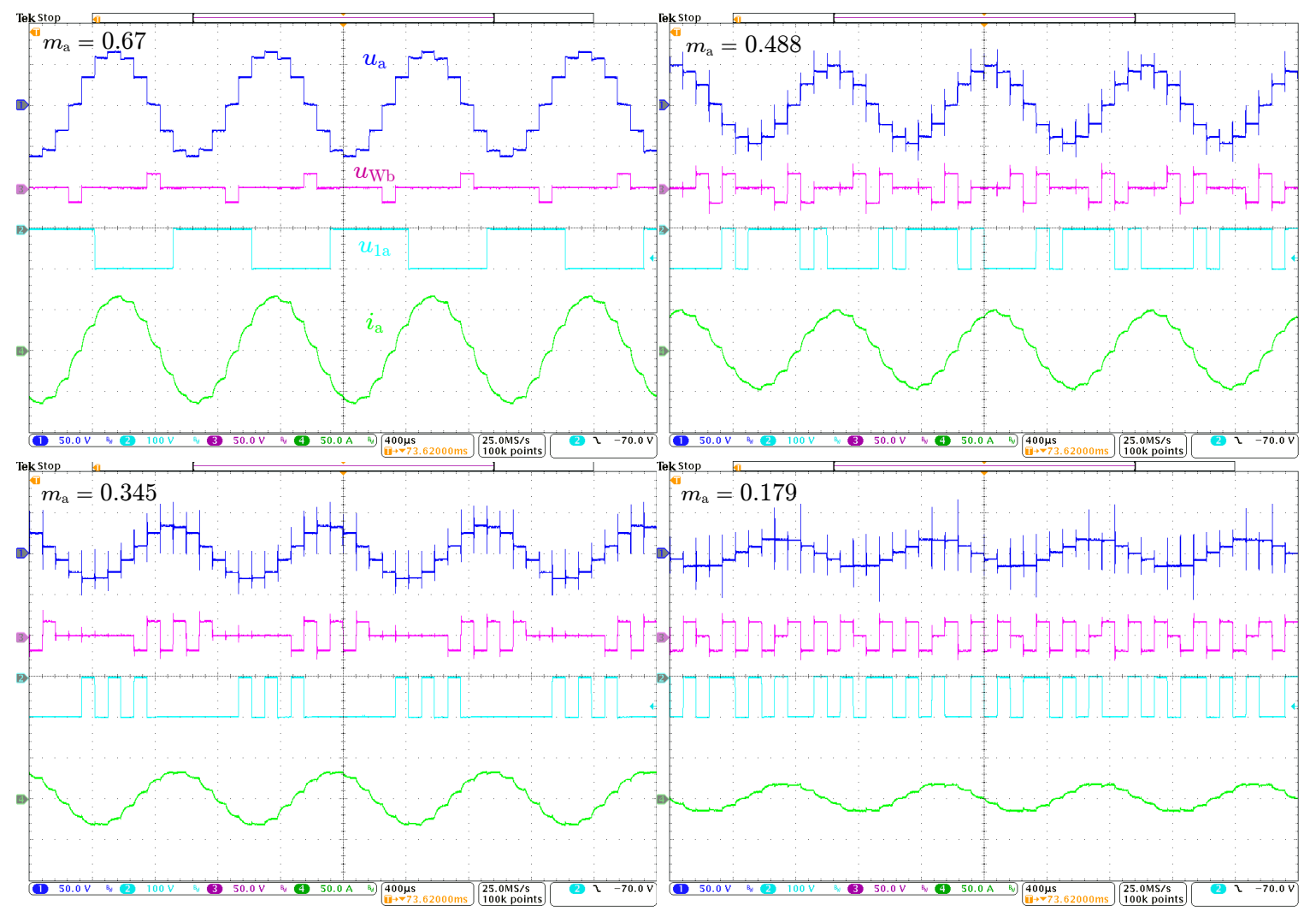

Figure 13. The output phase, leg, and coil $N_{\mathrm{B}}$ voltages and phase currents of the 12-pulse modular VSI with two-level modules for CQ-PAM control.

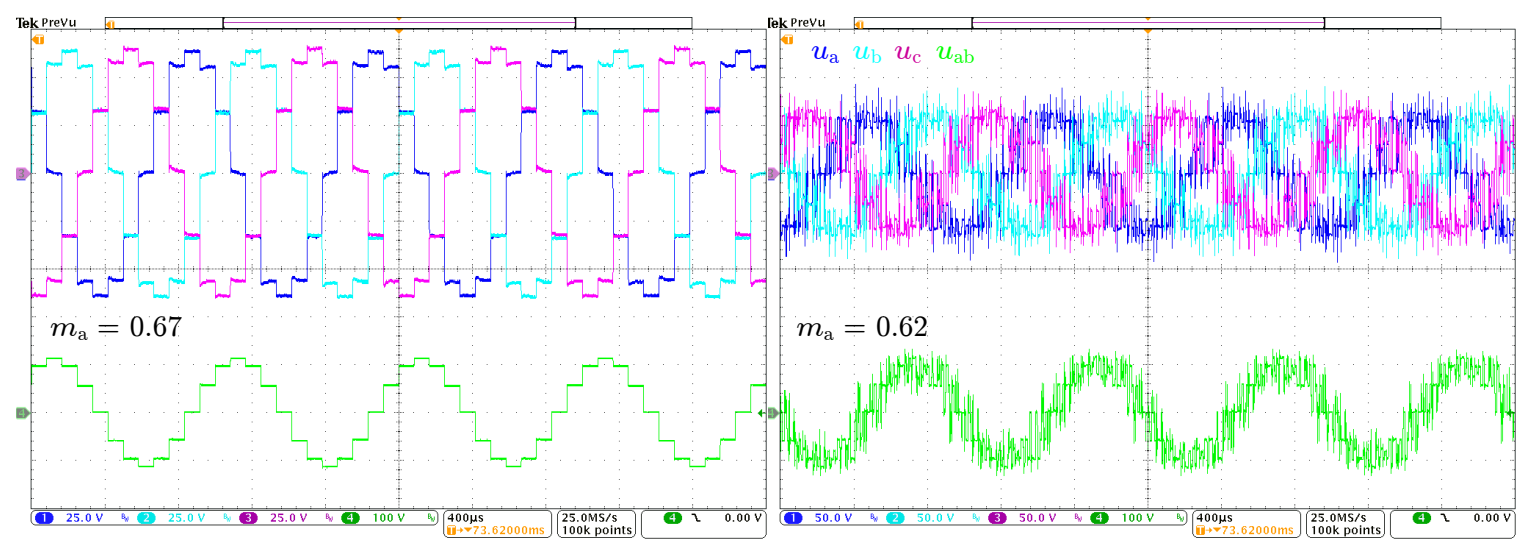

Figure 14. Output voltages for CQ-PAM (left) and space-vector pulse width modulation (SVPWM) (right) control.

The quality of output voltage and current will improve significantly with the increase in the number of inverter levels, as exemplified in Figures 16 and 17, which provide an initial comparison between the modular VSIs with two-level and three-level inverter modules. What is more, increasing the number of levels significantly increases the amplitude resolution of the CQ-PAM and reduces the voltage stresses of individual transistors. Consequently, the use of multilevel component inverters in the modular VSIs with coupled reactors will contribute to increased attractiveness of the considered topology. 


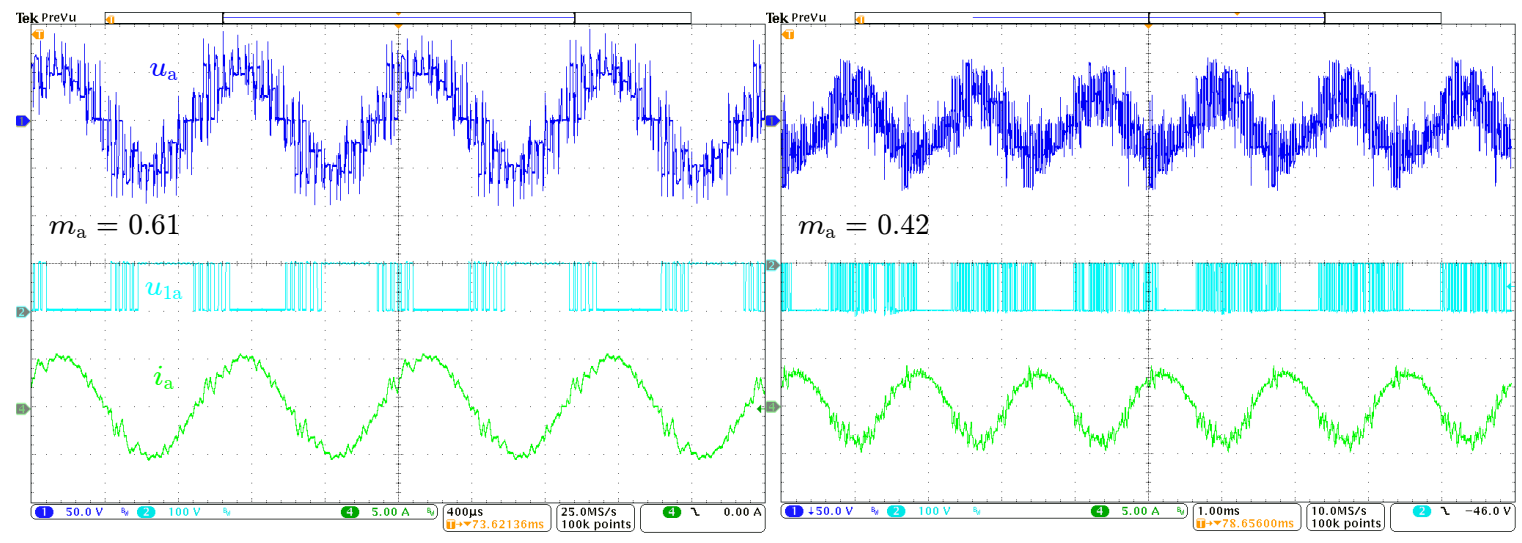

Figure 15. Example output voltages and currents for SVPWM control.

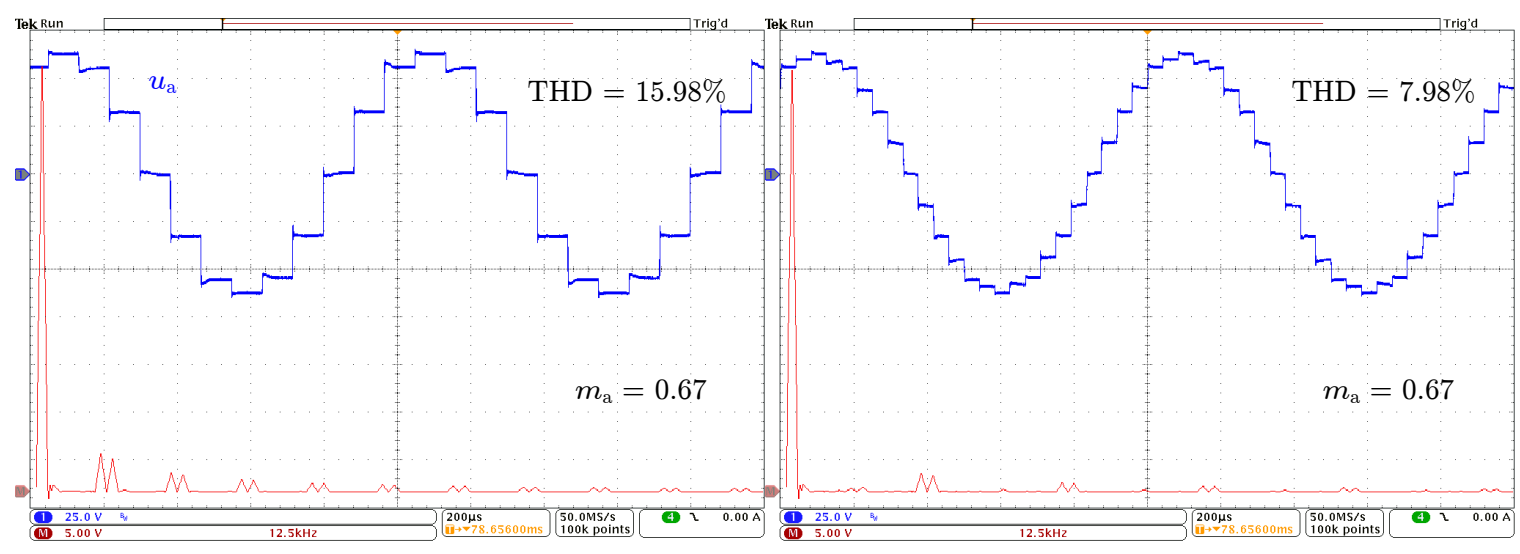

Figure 16. Output voltages and their spectra for the modular VSI with two-level (left) and three-level (right) modules.

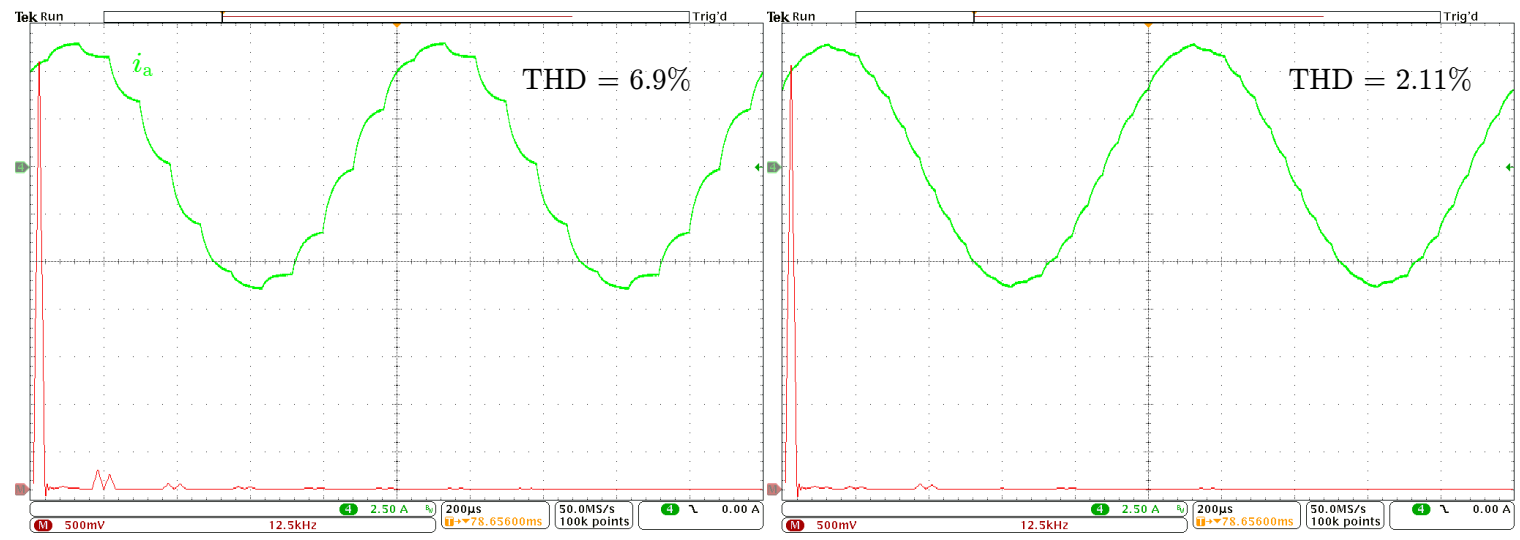

Figure 17. Load currents and their spectra for the modular VSI with two-level (left) and three-level (right) modules.

The modularity of the considered topology is an important advantage in itself. It allows, inter alia, even distribution of the overall power transferred by the inverter between the reduced-power modules. This feature is illustrated in Figure 18, which shows the phase currents of the component inverters $\left(i_{1 \mathrm{a}}\right.$, $i_{2 \mathrm{a}}$ ) and the resultant load currents $\left(i_{\mathrm{a}}\right)$. As can be seen, the component inverter currents have the same amplitude close to half of the load current. The modularity also improves operational reliability of the considered topology, because it can continue working in case of a failure of one component inverter. 


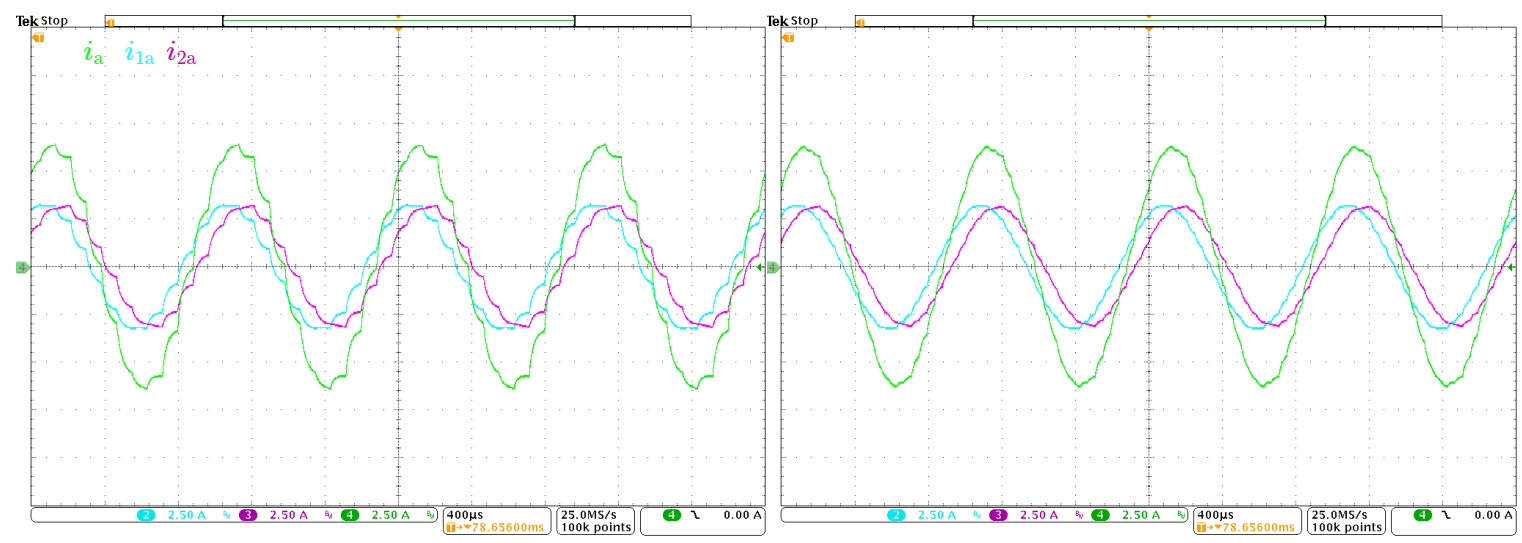

Figure 18. Phase currents of component inverters and the corresponding load currents of the modular VSI with two-level (left) and three-level (right) component inverters.

\section{Conclusions}

A hybrid approach to the output voltage control of modular VSI with coupled reactors has been proposed and discussed, including a novel coarsely quantized PAM and space-vector PWM based on the use of barycentric coordinates. Note that the use of these coordinates makes the SVPWM computations feasible and transparent even for such complex space-vector diagrams as those of the considered inverter topologies. The feasibility of the proposed solution has been verified by simulations and laboratory tests of the 12-pulse modular VSI with two-level and three-level component inverters. The use of multilevel inverter modules significantly improves the quality of output voltages and increases the attractiveness of the considered topology and the CQ-PAM, especially for application in high-speed motor drives (research into the latter application is planned for near future). It is also worth noting that the proposed solutions in modulation, although validated for particular inverter topologies, can be equally applicable to other topologies characterized by rich space-vector diagrams, including a variety of modular multipulse inverters.

Author Contributions: Conceptualization, K.J.S. and R.S.; methodology, K.J.S. and R.S.; software, K.J.S. and C.S.; validation, R.S., P.S., and C.S.; formal analysis, P.S. and J.N.; investigation, R.S., K.J.S., and C.S.; resources, K.J.S. and R.S.; data curation, R.S. and P.S.; writing-original draft preparation, K.J.S. and R.S; writing-review and editing, K.J.S., R.S., P.S. J.N., and C.S.; visualization, K.J.S., R.S., and C.S.; supervision, P.S., A.U., and J.N.; funding acquisition, P.S., J.N., and A.U. All authors have read and agreed to the published version of the manuscript.

Funding: This work was supported by the LINTE² Laboratory, Gdańsk University of Technology, Grant DS 033784, and the Government of the Russian Federation, Grant 08-08.

Conflicts of Interest: The authors declare no conflict of interest.

\section{References}

1. Strzelecki, R.; Sak, T.; Zolov, P.D.; Moradewicz, A.; Grabarek, M. Multi-pulse VSC arrangements with coupled reactors. In Proceedings of the 2016 IEEE 2nd Annual Southern Power Electronics Conference (SPEC), Auckland, New Zealand, 5-8 December 2016; pp. 1-6. [CrossRef]

2. Singh, B.; Bhuvaneswari, G.; Garg, V. Harmonic mitigation using 12-pulse AC-DC converter in vector-controlled induction motor drives. IEEE Trans. Power Deliv. 2006, 21, 1483-1492. [CrossRef]

3. Choi, S.; Oh, J.; Cho, J. Multi-pulse converters for high voltage and high power applications. In Proceedings of the IPEMC 2000, Third International Power Electronics and Motion Control Conference (IEEE Cat. No.00EX435), Beijing, China, 15-18 August 2000; Volume 3, pp. 1019-1024.

4. Yang, T.; Bozhko, S.; Asher, G. Functional Modeling of Symmetrical Multipulse Autotransformer Rectifier Units for Aerospace Applications. IEEE Trans. Power Electron. 2015, 30, 4704-4713. [CrossRef]

5. Singh, B.; Gairola, S.; Singh, B.N.; Chandra, A.; Al-Haddad, K. Multipulse AC-DC Converters for Improving Power Quality: A Review. IEEE Trans. Power Electron. 2008, 23, 260-281. [CrossRef] 
6. Walker, L.H. 10-MW GTO converter for battery peaking service. IEEE Trans. Ind. Appl. 1990, $26,63-72$. [CrossRef]

7. Pietkiewicz, A.; Biner, H. Novel low harmonic three-phase 12-pulse inverter. In Proceedings of the International Symposium on Power Electronics Power Electronics, Electrical Drives, Automation and Motion, Sorrento, Italy, 20-22 June 2012; pp. 837-842. [CrossRef]

8. Singh, B.; Hussain, I. Grid integration of single stage solar PV power generating system using 12-pulse VSC. In Proceedings of the 2014 IEEE 6th India International Conference on Power Electronics (IICPE), Kurukshetra, India, 8-10 December 2014; pp. 1-6.

9. Geethalakshmi, B.; Dananjayan, P. A Combined Multipulse-Multilevel Inverter Suitable For High Power Applications. Int. J. Comput. Electr. Eng. (IJCEE) 2010, 2, 257-261. [CrossRef]

10. Soto, D.; Green, T.C. A comparison of high-power converter topologies for the implementation of FACTS controllers. IEEE Trans. Ind. Electron. 2002, 49, 1072-1080. [CrossRef]

11. Chen, Z.; Spooner, E. Voltage source inverters for high-power, variable-voltage DC power sources. IEE Proc. Gener. Transm. Distrib. 2001, 148, 439-447. [CrossRef]

12. Strzelecki, R.; Sak, T.; Strzelecka, N. Method and System to Converting of Electrical Energy with the Use of Multilevel Inverters Connected in Parallel. Polish Patent PL 228547, 30 April 2018.

13. Oguchi, K.; Maeda, G.; Hoshi, N.; Kubata, T. Coupling rectifier systems with harmonic cancelling reactors. IEEE Ind. Appl. Mag. 2001, 7, 53-63. [CrossRef]

14. Paice, D.; Society, I.I.A. Power Electronic Converter Harmonics: Multipulse Methods For Clean Power; Electrical Engineering/Power and Energy Engineering; IEEE Press: Piscataway, NJ, USA, 1996.

15. Iwaszkiewicz, J.; Mysiak, P. Supply System for Three-Level Inverters Using Multi-Pulse Rectifiers with Coupled Reactors. Energies 2019, 12. [CrossRef]

16. Shih, D.; Hung, L.; Young, C. The harmonic elimination strategy for a 24-pulse converter with unequal-impedance phase-shift transformers. In Proceedings of the 2013 1st International Future Energy Electronics Conference (IFEEC), Tainan, Taiwan, 3-6 November 2013; pp. 783-788. [CrossRef]

17. Biela, J.; Hassler, D.; Schönberger, J.; Kolar, J.W. Closed-Loop Sinusoidal Input-Current Shaping of 12-Pulse Autotransformer Rectifier Unit With Impressed Output Voltage. IEEE Trans. Power Electron. 2011, 26, 249-259. [CrossRef]

18. Schwager, L.; Tüysüz, A.; Zwyssig, C.; Kolar, J.W. Modeling and Comparison of Machine and Converter Losses for PWM and PAM in High-Speed Drives. IEEE Trans. Ind. Appl. 2014, 50, 995-1006. [CrossRef]

19. Ismagilov, F.R.; Uzhegov, N.; Vavilov, V.E.; Bekuzin, V.I.; Ayguzina, V.V. Multidisciplinary Design of Ultra-High-Speed Electrical Machines. IEEE Trans. Energy Convers. 2018, 33, 1203-1212. [CrossRef]

20. Zwyssig, C.; Duerr, M.; Hassler, D.; Kolar, J.W. An Ultra-High-Speed, 500000 rpm, 1 kW Electrical Drive System. In Proceedings of the 2007 Power Conversion Conference-Nagoya, Nagoya, Japan, 2-5 April 2007; pp. 1577-1583. [CrossRef]

21. Buticchi, G.; Gerada, D.; Alberti, L.; Galea, M.; Wheeler, P.; Bozhko, S.; Peresada, S.; Zhang, H.; Zhang, C.; Gerada, C. Challenges of the Optimization of a High-Speed Induction Machine for Naval Applications. Energies 2019, 12. [CrossRef]

22. Gerada, D.; Mebarki, A.; Brown, N.L.; Gerada, C.; Cavagnino, A.; Boglietti, A. High-Speed Electrical Machines: Technologies, Trends, and Developments. IEEE Trans. Ind. Electron. 2014, 61, 2946-2959. [CrossRef]

23. Liang, Y.; Liang, D.; Jia, S.; Chu, S.; He, J. A Full-Speed Range Hybrid PWM Strategy for High-Speed Permanent Magnet Synchronous Machine Considering Mitigation of Current Harmonics. In Proceedings of the 2019 IEEE Energy Conversion Congress and Exposition (ECCE), Baltimore, MD, USA, 29 September-3 November 2019; pp. 1886-1890.

24. Zhang, Y.; Xu, D.; Yan, C.; Zou, S. Hybrid PWM Scheme for the Grid Inverter. IEEE J. Emerg. Select. Top. Power Electron. 2015, 3, 1151-1159. [CrossRef]

25. Szczepankowski, P.; Nieznański, J. Application of Barycentric Coordinates in Space Vector PWM Computations. IEEE Access 2019, 7, 91499-91508. [CrossRef]

26. April, G.; Olivier, G. A Novel Type of 12-Pulse Converter. IEEE Trans. Ind. Appl. 1985, IA-21, $180-191$. [CrossRef] 
27. Gong, G.; Drofenik, U.; Kolar, J.W. 12-pulse rectifier for more electric aircraft applications. In Proceedings of the 2003 IEEE International Conference on Industrial Technology, Maribor, Slovenia, 10-12 December 2003; Volume 2, pp. 1096-1101. [CrossRef]

28. Alabduljabbar, A.A.; Gerçek, C.Ö.; ATALIK, T.; Koç, E.; PARLAK, D.; Alsalem, F.S. Design and Implementation of a 12-Pulse TCR-Based SVC for Voltage Regulation. In Proceedings of the 2019 IEEE Jordan International Joint Conference on Electrical Engineering and Information Technology (JEEIT), Amman, Jordan, 9-11 April 2019; pp. 186-193. [CrossRef]

29. Lambert, G.; Costabeber, A.; Wheeler, P.; De Novaes, Y.R. A Unidirectional Insulated AC-DC Converter Based on the Hexverter and Multipulse-Rectifier. IEEE Trans. Power Electron. 2020, 35, 2363-2371. [CrossRef]

30. Mino, K.; Gong, G.; Kolar, J.W. Novel hybrid 12-pulse boost-type rectifier with controlled output voltage. IEEE Trans. Aerosp. Electron. Syst. 2005, 41, 1008-1018. [CrossRef]

31. Omara, A.M.; El-Nemr, M.K.; Moschopoulos, G. Parallel operation of voltage source inverters using SHE-PWM based on genetic algorithm. In Proceedings of the 2017 Nineteenth International Middle East Power Systems Conference (MEPCON), Cairo, Egypt, 19-21 December 2017; pp. 1292-1297.

32. Yang, K.; Feng, M.; Wang, Y.; Lan, X.; Wang, J.; Zhu, D.; Yu, W. Real-Time Switching Angle Computation for Selective Harmonic Control. IEEE Trans. Power Electron. 2019, 34, 8201-8212. [CrossRef]

33. Janabi, A.; Wang, B.; Czarkowski, D. Generalized Chudnovsky Algorithm for Real-Time PWM Selective Harmonic Elimination/Modulation: Two-Level VSI Example. IEEE Trans. Power Electron. 2020, 35, 5437-5446. [CrossRef]

(C) 2020 by the authors. Licensee MDPI, Basel, Switzerland. This article is an open access article distributed under the terms and conditions of the Creative Commons Attribution (CC BY) license (http:/ / creativecommons.org/licenses/by/4.0/). 